\title{
Article \\ Structural Vibration Control with the Implementation of a Tuned Mass Rocking Wall System
}

\author{
Wei Lin ${ }^{1}{ }^{1}$, Andong Wang ${ }^{1, *}$, Shanghong Chen ${ }^{1}, \mathrm{Ai} \mathrm{Qi}^{1}$ and Zhonggao Su ${ }^{2}$ \\ 1 College of Civil Engineering, Fuzhou University, Fuzhou 350108, China; cewlin@fzu.edu.cn (W.L.); \\ chenshanghong@fzu.edu.cn (S.C.); qikai@fzu.edu.cn (A.Q.) \\ 2 Bohai Engineering Testing Corporation, Fuzhou 350001, China; Rcjc@sina.com \\ * Correspondence: n190520030@fzu.edu.cn
}

Citation: Lin, W.; Wang, A.; Chen, S.; Qi, A.; Su, Z. Structural Vibration Control with the Implementation of a Tuned Mass Rocking Wall System. Buildings 2021, 11, 614. https:// doi.org/10.3390/buildings11120614

Academic Editors:

Maria Teresa De Risi

and Gerardo Mario Verderame

Received: 14 October 2021

Accepted: 30 November 2021

Published: 6 December 2021

Publisher's Note: MDPI stays neutral with regard to jurisdictional claims in published maps and institutional affiliations.

Copyright: (c) 2021 by the authors. Licensee MDPI, Basel, Switzerland. This article is an open access article distributed under the terms and conditions of the Creative Commons Attribution (CC BY) license (https:// creativecommons.org/licenses/by/ $4.0 /)$.
Abstract: A tuned mass rocking wall (TMRW)-frame structure system is proposed to improve the energy dissipation ability of the traditional rocking wall-frame system. Based on the energy dissipation principle of the traditional tuned mass damper (TMD), a TMRW is designed with proper mass and stiffness according to the dynamic characteristic of the host structure. Firstly, considering the presence of inherent structural damping, the dynamic amplification factor of the main mass was derived from the dynamic equations of the TMRW mechanism. A practical design table was then obtained after parameter study. Secondly, by taking a six-story frame structure as an example, the dynamic time-history analysis was conducted to study TMRW's seismic performance. The interstory drift ratios of the TMRW-frame, the traditional rocking wall-frame, and the frame structures were compared, and the seismic responses of the controlled and uncontrolled structures were also compared. The results demonstrate that the TMRW can effectively reduce the inter-story displacement of the host structure, and the lateral deformation mode of the host structure tends to be more uniform. However, compared with the traditional rocking wall-frame system, the proposed TMRW has less ability on coordinating deformation.

Keywords: tuned mass rocking wall (TMRW); parametric analysis; energy dissipation; frame structure; seismic performance

\section{Introduction}

A rocking wall-frame structure system is composed of a frame and a rocking wall that has limited rotation constraints at the bottom. The lateral connection device between the frame structure and the rocking wall ensures the collaborative work of the seismic system. Unlike traditional frame structures, the implemented rocking wall can coordinate inter-story deformation and avoid weak story failure under earthquake excitation. Alavi and Krawinkler [1] investigated the seismic performance of walls that are hinged at the base for frame structures with a wide range of periods. The results show that adding hinged walls is very effective in reducing the drift demands of weak stories and creating a more desirable distribution of story drifts. Through the dynamic time-history analysis, $\mathrm{Qu}$ and Ye [2] validated the effectiveness of the rocking wall-frame structure system in damage mechanism control and proposed a practical expression for calculating the stiffness demand of the rocking wall. Makris and Aghagholizadeh [3] derived the nonlinear dynamic equations of a single degree of freedom (SDOF) oscillator coupled with a rocking wall. The parametric analysis demonstrates that the stepping rocking wall is effective in controlling the displacement of relatively flexible structures. In contrast, the hinged rocking wall increases the displacement with a heavier wall being more detrimental. In recent years, many scholars summarized the existing research results of rocking wall-frame structure, expounded design methods of the wall and wall joints, and pointed out the further research emphasis of rocking wall [4-6]. 
Despite the effectiveness of the rocking wall, there are some deficiencies in its energy dissipation. In general, the rocking wall has difficulty reducing the inter-story displacement of the frame structure, and may even amplify the displacement responses of the host structure. Accordingly, energy dissipation dampers combined with rocking walls have been proposed to solve the shortcoming. Taking the eleven-story steel-reinforced concrete frame structure as an example, steel dampers equipped between the frame and the wall over the structural height were proposed by Qu et al. [7,8]. With the protection of the rocking wall and energy dissipation devices, damage to the host structure can be significantly reduced. Feng et al. [9] proposed a rocking wall-frame structure with buckling-restrained braces in base to suppress the displacement responses of the structure when subjected to a strong earthquake. Guo et al. [10] examined the influence of the distributed control devices (e.g., dampers installed at each floor level) on the seismic responses of rocking wall-frame structures. The results indicate that distributed control devices can sufficiently suppress the inter-story drift of the host structure. Coupled to the stepping rocking wall with the supplemental damping device along its sides, a yielding SDOF oscillator was proposed by Aghagholizadeh and Makris [11]. The parametric analysis of the inelastic system shows that the supplemental damping device can reduce structural responses for buildings with longer preyielding periods, but the effect is not obvious.

Neglecting the fact that a rocking wall can also function as a tuned mass substructure, the coupling between the rocking wall and other energy dissipation elements increases the material cost and construction difficulty. A PNTTMD system was proposed by Xiang and Nishitani [12], in which the rocking wall was designed as a long and narrow pendulum component performed as a TMD. Di Egidio et al. [13] proposed a rigid rocking block that worked as a TMD. When connected to the lowest part of the frame structure, this new control device can significantly reduce the drift of the top floor and lateral displacement of the bottom. The second author of this paper proposed a TMRW-frame structure system based on the energy dissipation principle of the traditional TMD [14]. The proposed TMRW can still hold most of the advantages of traditional rocking walls such as deformation coordination. And more vibration energy can be dissipated when the rocking wall is designed as a TMD system with a large mass.

In this study, the basic equations of motions of TMRW under harmonic excitation are derived. While neglected in the previous study, the inherent structural damping and harmonic base excitation are now included in these equations. To improve the seismic performance of the TMRW system, the optimal parameter design is conducted with both analytical and numerical methods. And then, a six-story frame structure is taken as an example, the seismic responses are compared with those of the rocking wall-frame system, as well as the proposed TMRW system. The applicability and superiority of the proposed TMRW system are then validated.

\section{Theoretical Analysis}

As shown in Figure 1, the rocking wall can create a uniform distribution of story drift with the large stiffness of horizontal connections. The TMRW-frame structure, a new structural system, is developed from the traditional rocking wall-frame structure. According to the frequency ratio design, the mass of the rocking wall and the stiffness of horizontal connections in Figure 1 are reasonably selected. When the vibration occurs, TMRW can absorb the vibration energy of the structure by resonating with the controlled vibration mode of the host structure. Therefore, the energy dissipation capacity of the rocking wall can be greatly improved after being correctly designed. 


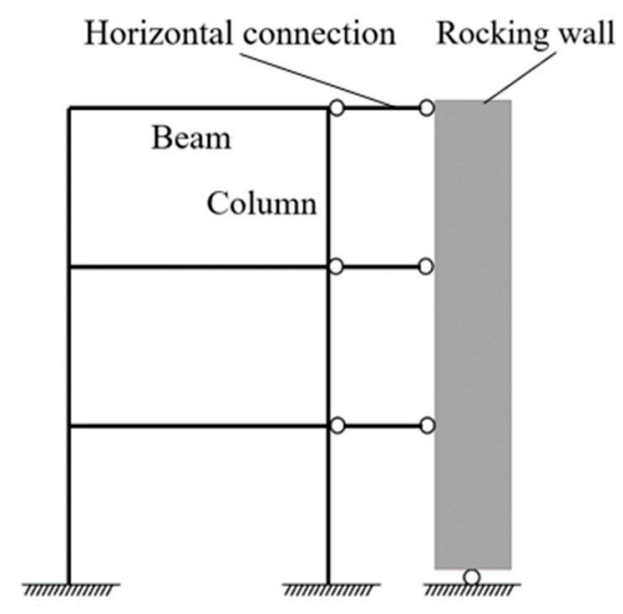

Figure 1. Rocking wall-frame structure system.

\subsection{TMRW-1 Control with No Damping}

Beams, columns, walls, and other components in the frame structure contribute to the energy dissipation, inertial, and elastic properties of the structure. After the controlled mode of the structure is determined, the frame structure can be simplified into an SDOF structure and each of the above properties is respectively concentrated in the damping, mass, and stiffness components. Hinged at the base, the rocking wall is connected with the SDOF structure by a link with a certain stiffness. Unconsidering the damping, the controlled system in Figure 2 consists of a mass block, springs, and a hinged rocking wall.

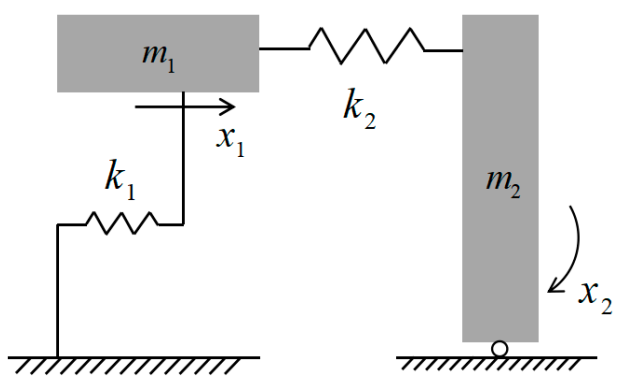

Figure 2. Schematic model of TMRW-1.

Under the external excitation, the dynamic equations of the TMRW-1 mechanism are given as

$$
\begin{gathered}
m_{1} \ddot{x}_{1}(t)+\left(k_{1}+k_{2}\right) x_{1}(t)-k_{2} h x_{2}(t)=P_{1}(t) \\
I_{2} \ddot{x}_{2}(t)-k_{2} h x_{1}(t)+k_{2} h^{2} x_{2}(t)=P_{2}(t)
\end{gathered}
$$

where:

$m_{1}=$ the main mass;

$I_{2}=$ the moment of inertia of the TMRW, $I_{2}=m_{2} h^{2} / 3$;

$k_{1}=$ the main spring stiffness;

$k_{2}=$ the spring stiffness of the TMRW;

$h=$ the structural height;

$P_{1}(t)=$ the force acting on the main mass with the same direction as $x_{1}$. Under harmonic main mass excitation, $P_{1}(t)=P_{0} \sin (\omega t)$. In case of harmonic base excitation with acceleration $\ddot{x}_{g}(t)=X_{g_{0}} \sin (\omega t)$, it is given as $P_{1}(t)=-m_{1} \ddot{x}_{g}(t)$.

$P_{2}(t)=$ the force acting on the rocking wall with same direction as $x_{2}$. It is given as

$$
P_{2}(t)= \begin{cases}0 & \text { for main mass excitation } \\ -\frac{1}{2} m_{2} h \ddot{x}_{g}(t) & \text { for base excitation }\end{cases}
$$


The steady-state solutions of $x_{1}(t)$ and $x_{2}(t)$ can be assumed

$$
\begin{aligned}
& x_{1}(t)=X_{1} \sin (\omega t) \\
& x_{2}(t)=X_{2} \sin (\omega t)
\end{aligned}
$$

Using above Equations (3) and (4), we can derive the displacement amplitudes of the structure when subjected to a harmonic main mass excitation

$$
\begin{aligned}
& X_{1}=\frac{\left(k_{2} h^{2}-I_{2} \omega^{2}\right) P_{0}}{\left(k_{1}+k_{2}-m_{1} \omega^{2}\right)\left(k_{2} h^{2}-I_{2} \omega^{2}\right)-\left(k_{2} h\right)^{2}} \\
& X_{2}=\frac{k_{2} h P_{0}}{\left(k_{1}+k_{2}-m_{1} \omega^{2}\right)\left(k_{2} h^{2}-I_{2} \omega^{2}\right)-\left(k_{2} h\right)^{2}}
\end{aligned}
$$

To facilitate further discussion, we introduce the following notations

$\mu=$ the ratio of TMRW mass to main mass, $\mu=m_{2} / m_{1}$;

$\omega_{n}=$ the natural frequency of main mass, $\omega_{n}^{2}=k_{1} / m_{1}$

$\omega_{d}=$ the natural frequency of TMRW mass, $\omega_{d}^{2}=k_{2} h^{2} / I_{2}$

$f=$ the frequency ratio, $f=\omega_{d} / \omega_{n}$;

$\omega=$ the harmonic excitation frequency;

$g=$ the ratio of excitation frequency to the natural frequency of $m_{1}, g=\omega / \omega_{n}$;

$\delta_{\text {st }}=$ the static displacement of main mass under $P_{0}, \delta_{\text {st }}=P_{0} / k_{1}$;

$\bar{\delta}_{\mathrm{st}}=$ the static displacement of main mass under $-m_{1} X_{g_{0}}, \bar{\delta}_{\mathrm{st}}=-m_{1} X_{g_{0}} / k_{1}$.

Using the above parameters, we can rewrite Equation (5) to obtain the dynamic amplification factor of the main mass.

$$
\frac{X_{1}}{\delta_{\text {st }}}=\frac{g^{2}-f^{2}}{1 / 3 \mu g^{2} f^{2}-\left(g^{2}-1\right)\left(g^{2}-f^{2}\right)}
$$

When the numerator in the above formula is zero, the amplitude of the main mass is equal to zero, so there is

$$
g^{2}-f^{2}=0
$$

When the structure works under resonance, $\omega=\omega_{n}$, the expression for calculating the stiffness parameter is given as

$$
f=1, k_{2}=\frac{m_{2} \omega_{n}^{2}}{3}
$$

Using Equations (3) and (4), we can also derive the amplification factor of the main mass when subjected to harmonic base excitation.

$$
\frac{X_{1}}{\bar{\delta}_{\mathrm{st}}}=\frac{g^{2}-\left(1+\frac{\mu}{2}\right) f^{2}}{1 / 3 \mu g^{2} f^{2}-\left(g^{2}-1\right)\left(g^{2}-f^{2}\right)}
$$

The corresponding expressions for calculating TMRW parameters can be given as

$$
f=\sqrt{\frac{2}{2+\mu}}, k_{2}=\frac{2 m_{2} \omega_{n}^{2}}{3(2+\mu)}
$$

\subsection{TMRW-2 Control with Damping}

In the actual vibration system, the structure always has a certain amount of damping. Considering the presence of structural damping, the schematic model of TMRW-2 is shown in Figure 3. 


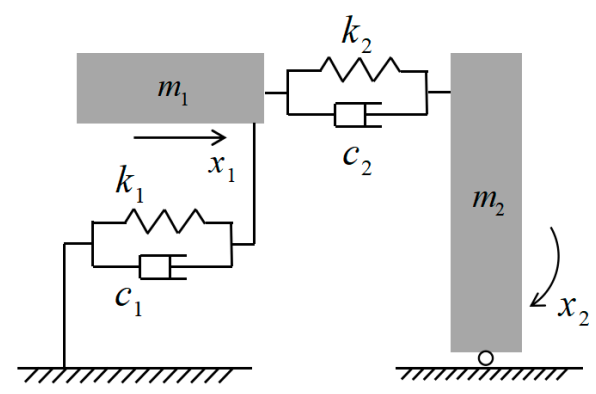

Figure 3. Schematic model of TMRW-2.

Referring to Figure 3, the equations of motion for the TMRW-2 mechanism are

$$
\begin{gathered}
m_{1} \ddot{x}_{1}(t)+\left(c_{1}+c_{2}\right) \dot{x}_{1}(t)-c_{2} h \dot{x}_{2}(t)+\left(k_{1}+k_{2}\right) x_{1}(t)-k_{2} h x_{2}(t)=P_{1}(t) \\
I_{2} \ddot{x}_{2}(t)-c_{2} h \dot{x}_{1}(t)+c_{2} h^{2} \dot{x}_{2}(t)-k_{2} h x_{1}(t)+k_{2} h^{2} x_{2}(t)=P_{2}(t)
\end{gathered}
$$

where $c_{1}$ is the main mass damping; $c_{2}$ is the TMRW damping.

The steady-state solutions of displacement can be assumed

$$
\begin{aligned}
& x_{1}(t)=X_{1} e^{i\left(\omega t+\theta_{1}\right)} \\
& x_{2}(t)=X_{2} e^{i\left(\omega t+\theta_{2}\right)}
\end{aligned}
$$

Substituting above Equations (14) and (15) into Equations (12) and (13), the displacement amplitude of the main mass when subjected to a harmonic main mass excitation is determined by

$$
\begin{gathered}
X_{1} e^{i \theta_{1}}=\frac{A}{B} \\
A=\left(k_{2} h^{2}-I_{2} \omega^{2}+i \omega c_{2} h^{2}\right) P_{0} \\
B=\left[\left(k_{1}-m_{1} \omega^{2}\right)\left(k_{2} h^{2}-I_{2} \omega^{2}\right)-I_{2} k_{2} \omega^{2}-c_{1} c_{2} \omega^{2} h^{2}\right] \\
+i \omega\left[c_{2}\left(k_{1} h^{2}-m_{1} \omega^{2} h^{2}-I_{2} \omega^{2}\right)+c_{1}\left(k_{2} h^{2}-I_{2} \omega^{2}\right)\right]
\end{gathered}
$$

For brevity, additional symbols are introduced as follows

$\zeta_{s}=$ the damping ratio of main mass, $\zeta_{s}=c_{1} / 2 m_{1} \omega_{n}$;

$\zeta_{d}=$ the damping ratio of TMRW, $\zeta_{d}=c_{2} h^{2} / 2 I_{2} \omega_{d}$.

Using the symbols above and Equations (16)-(18), the amplification factor of the main mass is given as

$$
\begin{gathered}
\frac{X_{1}}{\delta_{\mathrm{st}}}=\left[\frac{\left(2 \zeta_{d} g\right)^{2}+\left(g^{2}-f^{2}\right)^{2}}{Z}\right]^{\frac{1}{2}} \\
Z=\left[\frac{1}{3} \mu g^{2} f^{2}+4 \zeta_{s} \zeta_{d} g^{2}-\left(g^{2}-1\right)\left(g^{2}-f^{2}\right)\right]^{2} \\
+g^{2}\left[2 \zeta_{d}\left(g^{2}-1+\frac{1}{3} \mu g^{2}\right)+2 \zeta_{s}\left(g^{2}-f^{2}\right)\right]^{2}
\end{gathered}
$$

In Equations (19) and (20), each parameter influences the dynamic amplification factor, thereby no analytical solution can be derived. However, some numerical methods can be adopted to obtain the optimal parameters of TMRW [15-17]. In this paper, the numerical search is based on a min-max approach. When the parameters $\mu$ and $\zeta_{s}$ are determined, many combinations of parameters $f$ and $\zeta_{d}$ are systematically considered until the peak response $\left(\mathrm{P}_{1}\right.$ or $\mathrm{P}_{2}$, Figure 4$)$ reaches a minimum. Since little damping exists in the real structure, the frequency ratio in Equation (9) gives a good starting value. After a numerical search, the peak surface of the amplification factor is shown in Figure 5. The lowest point of 
the peak surface corresponds to the case where vibration response is optimal. This optimal point yields $f_{\mathrm{opt}}$ and $\zeta_{d_{\mathrm{opt}}}$.

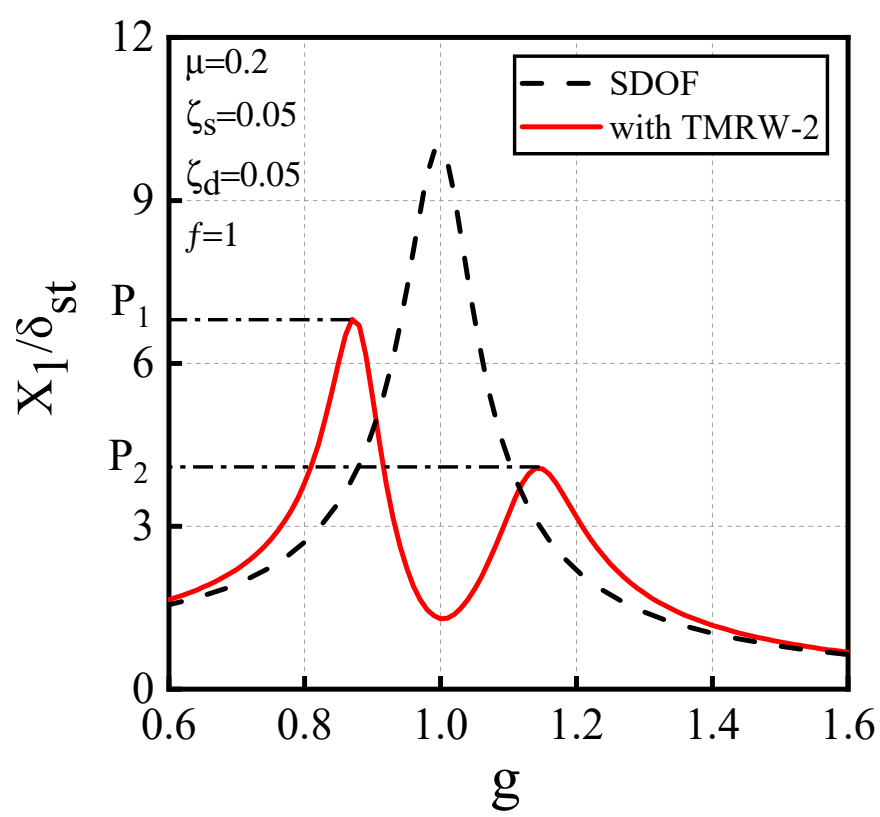

Figure 4. Example of damped system frequency response.

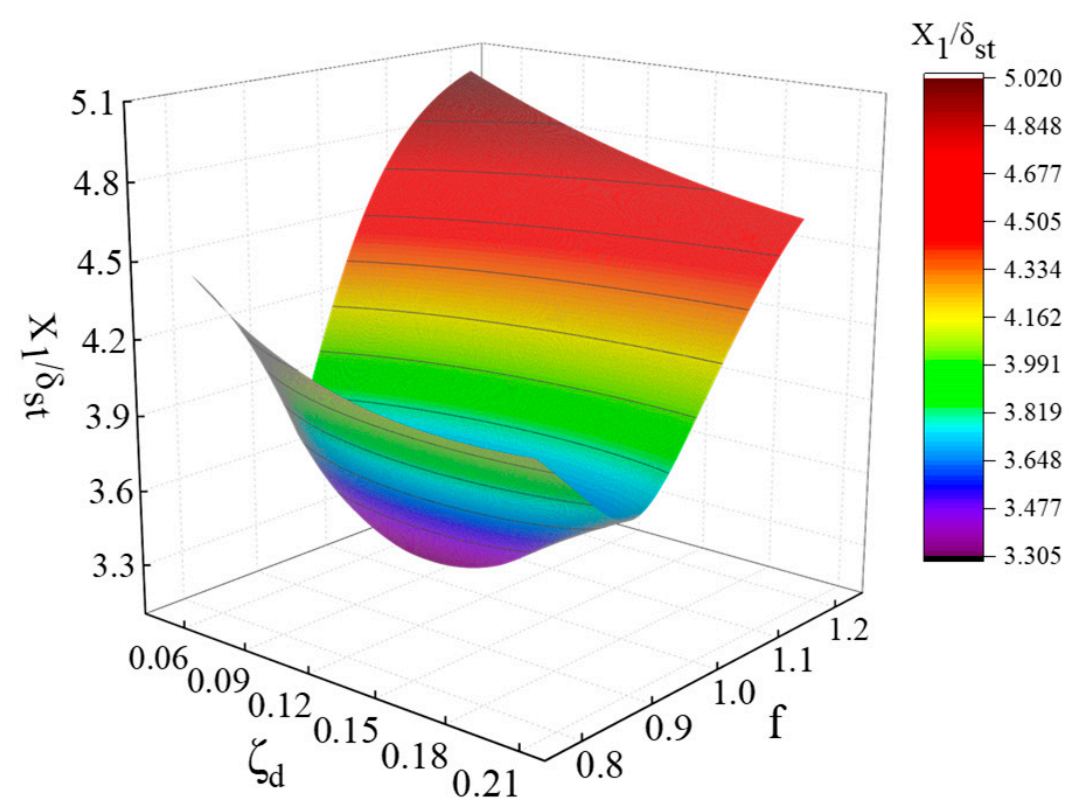

Figure 5. Peak surface of amplification factor $X_{1} / \delta_{\text {st }}$ for $\mu=0.1$ and $\zeta_{s}=0.1$.

To facilitate the design of a TMRW considering structural damping, the design table has been developed. Using the optimal parameters in Table 1, the optimal stiffness and the optimal damping can be calculated as

$$
\begin{gathered}
k_{\mathrm{opt}}=\frac{m_{2} f_{\mathrm{opt}}{ }^{2} \omega_{n}^{2}}{3} \\
c_{\mathrm{opt}}=\frac{2 m_{2} \omega_{n} \zeta_{d_{\mathrm{opt}} f_{\mathrm{opt}}}}{3}
\end{gathered}
$$


Table 1. Optimal parameters of TMRW: main mass excitation.

\begin{tabular}{cccccccc}
\hline $\begin{array}{c}\mu=0.2 \\
\zeta_{\boldsymbol{s}}(\%)\end{array}$ & $f_{\text {opt }}$ & $\boldsymbol{\zeta}_{\boldsymbol{d}_{\text {opt }}}$ & $\left(\frac{\boldsymbol{X}_{1}}{\delta_{\text {st }}}\right)_{\text {peak }}$ & $\begin{array}{c}\mu=0.4 \\
\boldsymbol{\zeta}_{\boldsymbol{s}}(\%)\end{array}$ & $f_{\text {opt }}$ & $\boldsymbol{\zeta}_{\boldsymbol{d}_{\text {opt }}}$ & $\left(\frac{\boldsymbol{X}_{1}}{\delta_{\text {st }}}\right)_{\text {peak }}$ \\
\hline 0.5 & 0.936 & 0.142 & 5.328 & 0.5 & 0.880 & 0.188 & 3.884 \\
1 & 0.934 & 0.146 & 5.101 & 1 & 0.878 & 0.186 & 3.767 \\
1.5 & 0.932 & 0.149 & 4.895 & 1.5 & 0.876 & 0.184 & 3.658 \\
2 & 0.930 & 0.149 & 4.706 & 2 & 0.873 & 0.190 & 3.554 \\
2.5 & 0.929 & 0.142 & 4.526 & 2.5 & 0.871 & 0.187 & 3.455 \\
3 & 0.927 & 0.143 & 4.358 & 3 & 0.869 & 0.184 & 3.362 \\
3.5 & 0.925 & 0.143 & 4.203 & 3.5 & 0.866 & 0.190 & 3.275 \\
4 & 0.923 & 0.144 & 4.059 & 4 & 0.864 & 0.186 & 3.191 \\
4.5 & 0.921 & 0.144 & 3.925 & 4.5 & 0.861 & 0.191 & 3.112 \\
5 & 0.919 & 0.144 & 3.800 & 5 & 0.859 & 0.186 & 3.036 \\
\hline
\end{tabular}

For the case when the TMRW-2 mechanism is subjected to a harmonic base excitation, the corresponding amplification factor of the main mass is given as

$$
\frac{X_{1}}{\bar{\delta}_{\mathrm{st}}}=\left\{\frac{\left(1+\frac{\mu}{2}\right)^{2}\left(2 \zeta_{d} g\right)^{2}+\left[g^{2}-\left(1+\frac{\mu}{2}\right) f^{2}\right]^{2}}{Z}\right\}^{\frac{1}{2}}
$$

Figure 6 and Table 2 show the corresponding peak surface of the amplification factor $X_{1} / \bar{\delta}_{\text {st }}$ and design table for obtaining TMRW parameters.

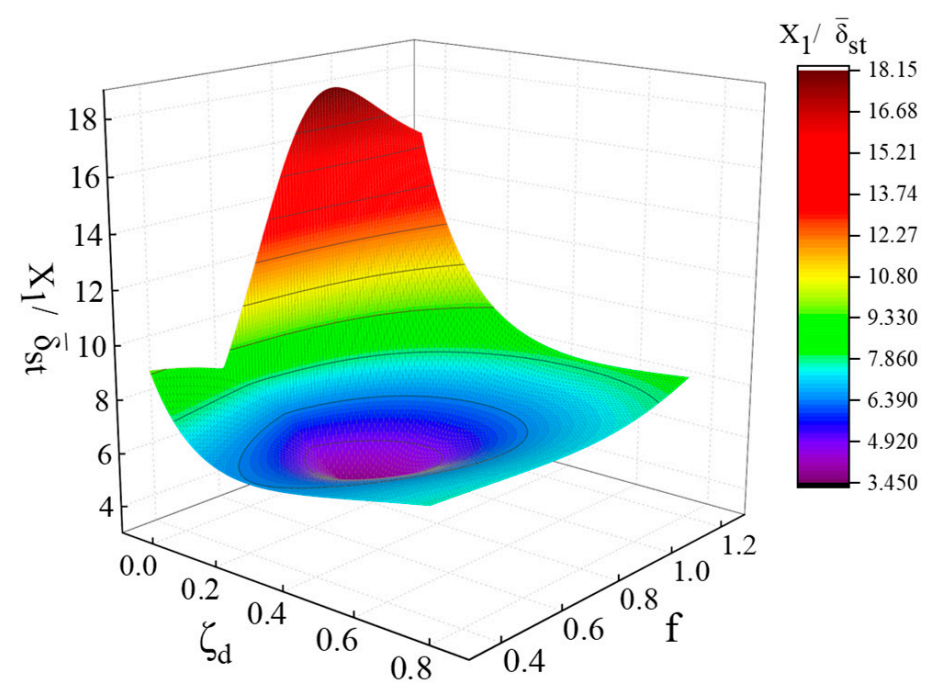

Figure 6. Peak surface of amplification factor $X_{1} / \bar{\delta}_{\text {st }}$ for $\mu=0.4$ and $\zeta_{s}=0.05$.

Table 2. Optimal parameters of TMRW: base excitation.

\begin{tabular}{cccccccc}
\hline $\begin{array}{c}\mu=0.2 \\
\zeta_{\boldsymbol{s}}(\boldsymbol{\%})\end{array}$ & $f_{\text {opt }}$ & $\boldsymbol{\zeta}_{\boldsymbol{d}_{\text {opt }}}$ & $\left(\frac{\boldsymbol{X}_{1}}{\bar{\delta}_{\text {st }}}\right)_{\text {peak }}$ & $\begin{array}{c}\mu=0.4 \\
\boldsymbol{\zeta}_{\boldsymbol{s}}(\%)\end{array}$ & $f_{\text {opt }}$ & $\boldsymbol{\zeta}_{\boldsymbol{d}_{\text {opt }}}$ & $\left(_{\overline{\boldsymbol{X}}_{\text {st }}}\right)_{\text {peak }}$ \\
\hline 0.5 & 0.911 & 0.141 & 5.732 & 0.5 & 0.835 & 0.181 & 4.467 \\
1 & 0.908 & 0.143 & 5.481 & 1 & 0.831 & 0.183 & 4.326 \\
1.5 & 0.905 & 0.145 & 5.252 & 1.5 & 0.827 & 0.184 & 4.193 \\
2 & 0.901 & 0.143 & 5.039 & 2 & 0.823 & 0.185 & 4.067 \\
2.5 & 0.898 & 0.145 & 4.843 & 2.5 & 0.818 & 0.183 & 3.949 \\
3 & 0.894 & 0.144 & 4.661 & 3 & 0.813 & 0.181 & 3.837 \\
3.5 & 0.890 & 0.142 & 4.492 & 3.5 & 0.809 & 0.183 & 3.732 \\
4 & 0.887 & 0.145 & 4.334 & 4 & 0.805 & 0.185 & 3.632 \\
4.5 & 0.883 & 0.145 & 4.186 & 4.5 & 0.800 & 0.184 & 3.537 \\
5 & 0.880 & 0.148 & 4.047 & 5 & 0.795 & 0.183 & 3.446 \\
\hline
\end{tabular}




\subsection{Comparison of Control Effect}

Using the formula of dynamic amplification factors above, Figure 7 compares the uncontrolled and controlled vibration responses. One can see that from the results, both TMRW-1 and TMRW-2 controlled systems can effectively control the response amplitude of the main mass. For the TMRW-1 controlled system, the dynamic amplification factor at the tuning frequency is equal to zero, while TMRW-2 control can improve the deterioration of damping performance caused by the excitation frequency variation.

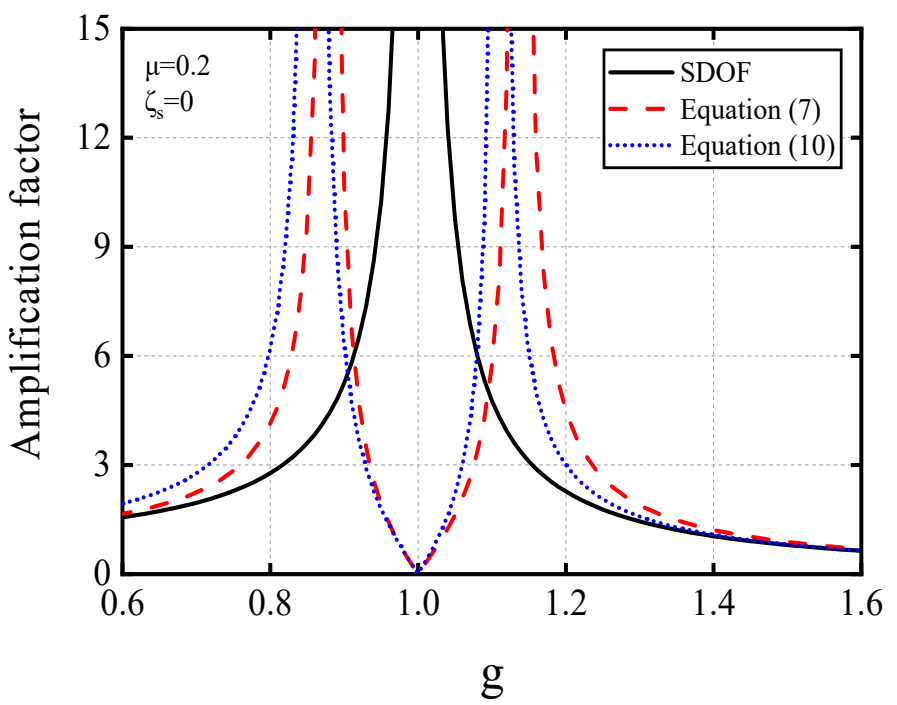

(a)

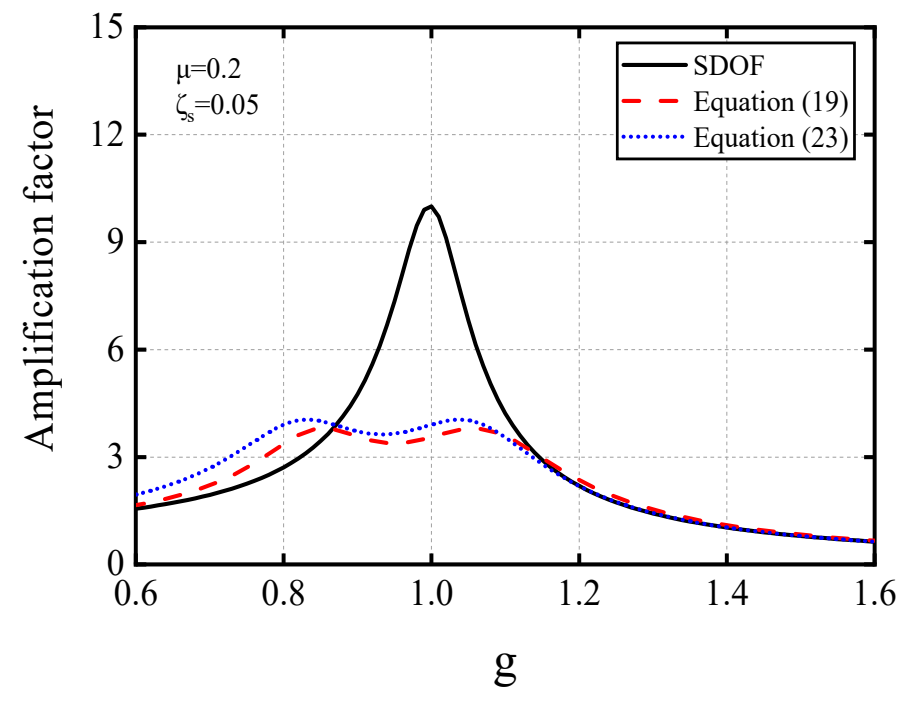

(b)

Figure 7. Control effect of the TMRW: (a) Undamped structure; (b) Damped structure.

\subsection{Design Example}

In the case of a harmonic base excitation, a TMRW is designed for a damped SDOF structure. Under moderate earthquakes, the related design problem of controlling a multi-degree-of-freedom structure with a dominant first-order mode will be similar to the problem discussed here.

Following Figure 3, a linear system is assumed to have the following characteristics

$$
\begin{gathered}
m_{1}=1000 \mathrm{~kg} \\
\zeta_{\mathrm{s}}=0.05 \\
\omega_{\mathrm{n}}=2 \pi \mathrm{rad} / \mathrm{s}
\end{gathered}
$$

If the TMRW mass is taken to be $40 \%$ of the main mass, then

$$
\begin{gathered}
\mu=0.4 \\
m_{2}=400 \mathrm{~kg}
\end{gathered}
$$

Using the above known values of $\mu$ and $\zeta_{s}$, the optimal TMRW parameters can be obtained from the min-max approach, or more easily from the design Table 2. One obtains

$$
\begin{gathered}
f_{\mathrm{opt}}=0.795 \\
\zeta_{d_{\mathrm{opt}}}=0.183
\end{gathered}
$$

Using $\omega_{\mathrm{n}}=2 \pi \mathrm{rad} / \mathrm{s}$ and Equations (21) and (22), the optimal parameters for stiffness and damping are found to be

$$
k_{\mathrm{opt}}=\frac{m_{2} f_{\mathrm{opt}}{ }^{2} \omega_{n}^{2}}{3}=3326.846 \mathrm{~N} / \mathrm{m}
$$




$$
c_{\mathrm{opt}}=\frac{2 m_{2} \omega_{n} \zeta_{\mathrm{dopt}_{\mathrm{opt}}} f_{\mathrm{op}}}{3}=243.762 \mathrm{~N} \cdot \mathrm{s} / \mathrm{m}
$$

Thus, all three parameters (mass, stiffness, and damping coefficient) of the TMRW are now known. And these complete the design of the TMRW which controls the natural mode of an SDOF structure.

\section{Structural Modeling}

The prototype structure of the analytical model is a six-story reinforced concrete frame structure in China. Figure 8 shows the simplified two-dimensional frame structure. Given a total height of $18.6 \mathrm{~m}$, the standard height is $3.6 \mathrm{~m}$ and the height of other floors is $3 \mathrm{~m}$. The lengths of the three bays are $6 \mathrm{~m}, 4 \mathrm{~m}$, and $6 \mathrm{~m}$, respectively. Based on the above frame structure, a TMRW-frame structure is established by adding a hinged rocking wall (Figure 8). Taking the ratio of wall stiffness to frame stiffness as the design principle, the thickness and width of the rocking wall are $0.35 \mathrm{~m}$ and $3 \mathrm{~m}$, respectively. The concrete compressive strength of the TMRW-frame structure is $26.8 \mathrm{MPa}$. The yield strength of the main reinforcement is $335 \mathrm{MPa}$.

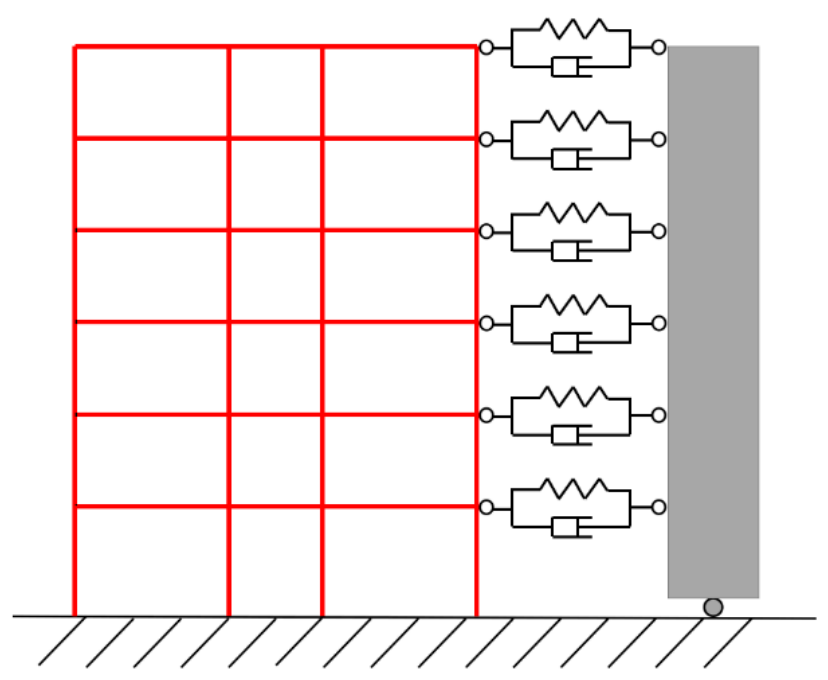

Figure 8. Structural analysis model.

The structural modeling is performed using ANSYS. The beams and columns in the structure are both stimulated by the linear finite strain beam element Beam188. Based on the principle of equivalent stiffness, the constitutive model of reinforced concrete members is simplified to be piecewise linear [18]. The design goal of the rocking wall is to keep elasticity under earthquake excitations, so the elastic Shell188 is adopted for the wall. Shell181 is a four-node element suitable for analyzing moderately-thick shell structures. The horizontal connections, connecting the rocking wall and the frame columns, are realized by Combin14 which is defined by two connected nodes, damping coefficients, and a spring constant. Using the design process of TMRW-2 in Section 2.4, the values of stiffness and damping coefficient in horizontal connections are listed in Table 3. Table 4 shows the first natural frequencies of structural models obtained from modal analysis results.

Table 3. The values of TMRW parameters from the lower to upper stories.

\begin{tabular}{ccc}
\hline Story & Stiffness (N/mm) & Damping (N.s/mm) \\
\hline 1 & 18.000 & 0.800 \\
2 & 32.940 & 1.464 \\
3 & 48.060 & 2.136 \\
4 & 63.000 & 2.800 \\
5 & 77.940 & 3.464 \\
6 & 93.060 & 4.136 \\
\hline
\end{tabular}


Table 4. The first natural frequencies of structures.

\begin{tabular}{cc}
\hline Type & Natural Frequencies (Hz) \\
\hline Frame & 1.6768 \\
Rocking wall-frame & 1.5322 \\
TMRW-frame & 0.9827 \\
\hline
\end{tabular}

Considering different factors of ground motion (type, intensity, duration, etc.), three earthquake excitations shown in Figure 9 are adopted in the dynamic analysis. The peak accelerations of these three seismic waves are set between $0.1 \mathrm{~g}$ and $0.2 \mathrm{~g}$. For each excitation case, uncontrolled and TMRW controlled scenarios are examined.

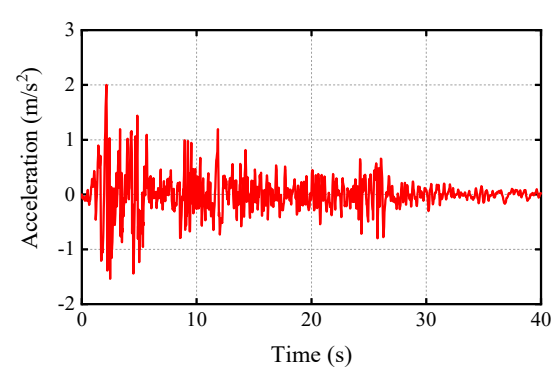

(a)

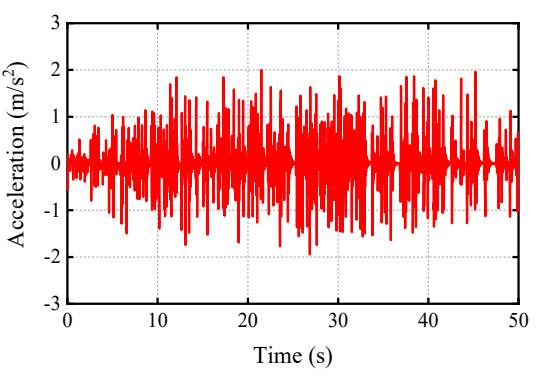

(b)

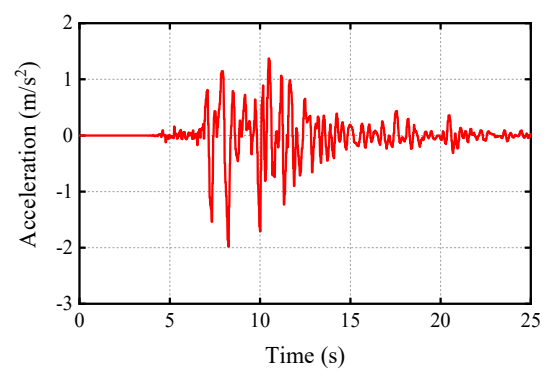

(c)

Figure 9. The three earthquakes used in this study: (a) El Centro; (b) Wenchuan; (c) Kobe.

\section{Vibration Control with TMRW}

\subsection{Inter-Story Drift}

Inter-story drift ratio (IDR) has a good correlation with the overall damage degree of multistory building structures. Figures 10-12 compare the IDRs of the uncontrolled frame, rocking wall-frame, and TMRW-frame structures under various earthquake excitations. For each excitation case, the middle floors of the frame structure experience large IDRs. After adding the TMRW, the IDR value of each floor can be greatly reduced, especially the middle floors. While the traditional rocking wall-frame structure has less ability to improve the IDRs of weak stories, even larger IDRs are obtained on higher floors. Nevertheless, the distribution of story drift in the rocking wall-frame structure is the most uniform. Thus, although the TMRW can reduce IDRs at each story, it sacrifices part of compatible deformation ability due to the reduction of connection stiffness.

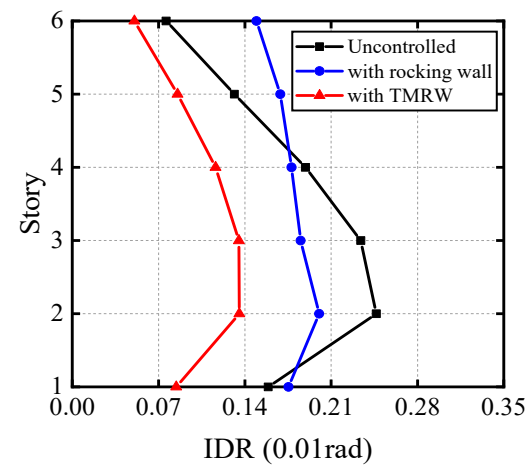

(a)

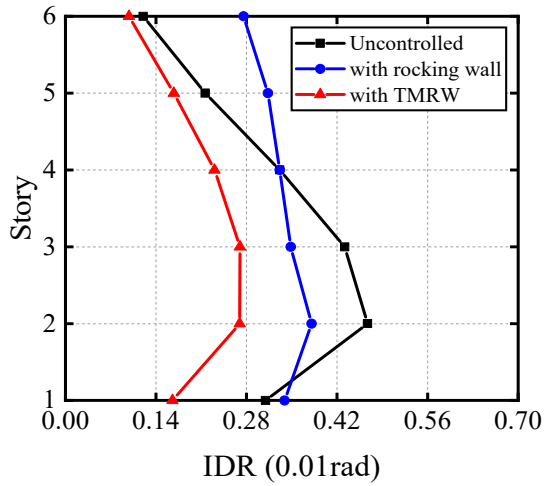

(b)

Figure 10. Comparison of the IDRs under El Centro excitation: (a) $0.1 \mathrm{~g}$ case; (b) $0.2 \mathrm{~g}$ case. 
The rocking wall and the TMRW can both create a more uniform inter-story drift. To better investigate the uniformity of deformation between stories, the drift concentration factor (DCF) is defined in Equation (24).

$$
\mathrm{DCF}=\frac{\max (\mathrm{IDR})}{\Delta / H}
$$

where $H$ is the total height of the building structure; $\Delta$ is the roof displacement.

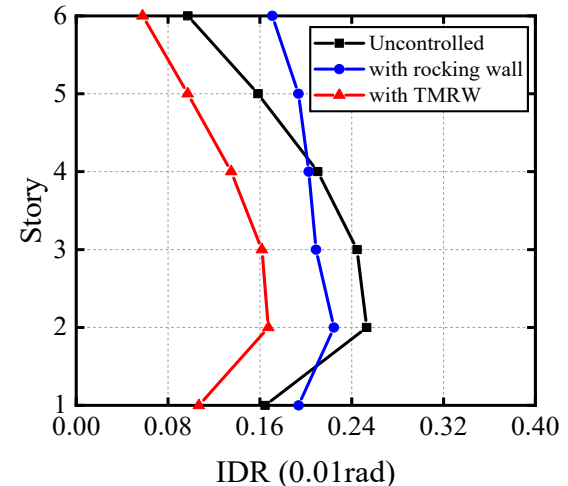

(a)

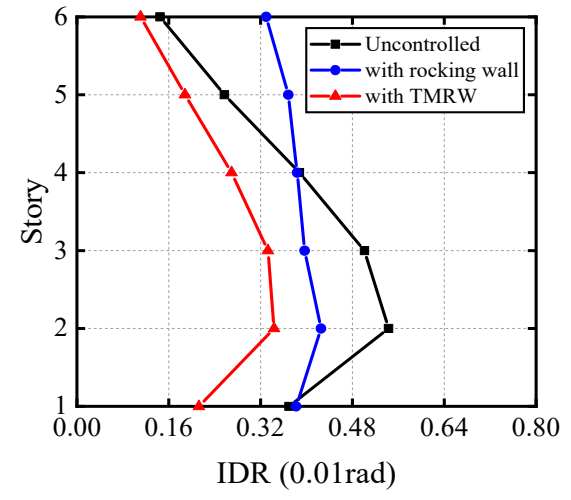

(b)

Figure 11. Comparison of the IDRs under Kobe excitation: (a) $0.1 \mathrm{~g}$ case; (b) $0.2 \mathrm{~g}$ case.

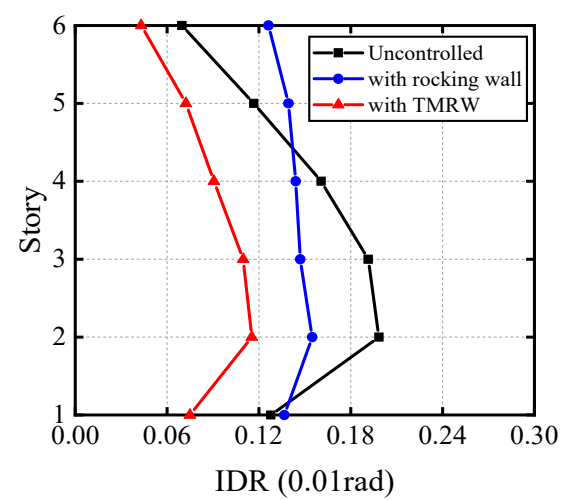

(a)

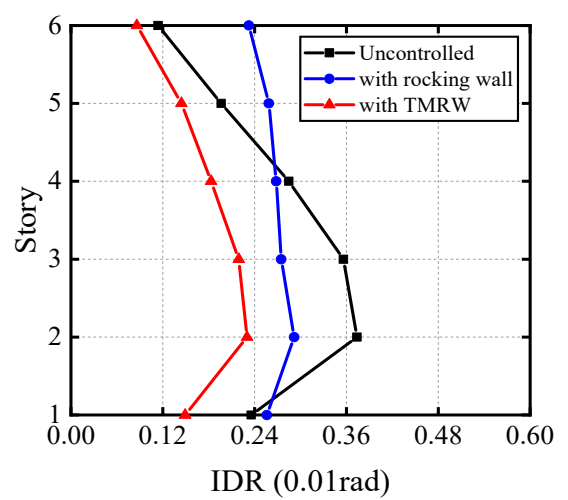

(b)

Figure 12. Comparison of the IDRs under Wenchuan excitation: (a) $0.1 \mathrm{~g}$ case; (b) $0.2 \mathrm{~g}$ case.

The effectiveness of the two walls in decreasing the inter-story drift concentration can be seen in Table 5. The results show that the drift concentration factors are reduced for the three ground motions by adding the wall, and the integrity of the host structure is thus increased. Additionally, compared with the traditional rocking wall, the ability of TMRW to improve inter-story drift concentration is reduced.

Table 5. DCF values of different structures.

\begin{tabular}{cccc}
\hline \multirow{2}{*}{ Excitation } & \multicolumn{3}{c}{ DCF } \\
\cline { 2 - 4 } & Uncontrolled & With TMRW & With Rocking Wall \\
\hline El Centro $(0.1 \mathrm{~g})$ & 1.436 & 1.325 & 1.144 \\
El Centro $(0.2 \mathrm{~g})$ & 1.494 & 1.333 & 1.150 \\
Kobe $(0.1 \mathrm{~g})$ & 1.351 & 1.348 & 1.129 \\
Kobe $(0.2 \mathrm{~g})$ & 1.479 & 1.428 & 1.135 \\
Wenchuan $(0.1 \mathrm{~g})$ & 1.394 & 1.339 & 1.119 \\
Wenchuan $(0.2 \mathrm{~g})$ & 1.445 & 1.359 & 1.125 \\
\hline
\end{tabular}




\subsection{Displacement Responses}

In the following analysis, the control effectiveness $\eta$ is used as a measure in assessing the control performance of the TMRW. The corresponding expression for calculating control effectiveness is given by

$$
\eta=\frac{R_{u}-R_{c}}{R_{u}} \times 100 \%
$$

where $R_{u}$ refers to the response of the uncontrolled frame structure; $R_{c}$ refers to the TMRWcontrolled response.

Time histories of uncontrolled, TMRW-controlled displacement responses on weak story are compared in Figure 13. In the figure, the amplitude of the earthquake excitation is set as $0.1 \mathrm{~g}$. One can see that from these results, the TMRW control can produce a good seismic performance on reducing earthquake-induced displacement. To further investigate the influence of the TMRW on the control effectiveness, the peak and rootmean-square (RMS) displacement responses are listed in Table 6. Both the peak and the RMS displacement responses on the second floor are effectively reduced. Under the low excitation intensities, TMRW systems achieve $45.9 \%$ and $66.5 \%$ reductions in the peak and RMS displacement. When the excitation intensities reach $0.2 \mathrm{~g}$, the reductions of TMRW systems are $44.2 \%$ and $54.6 \%$, respectively. Although the control performance is no better than the former, the impressive reduction is still obtained. 


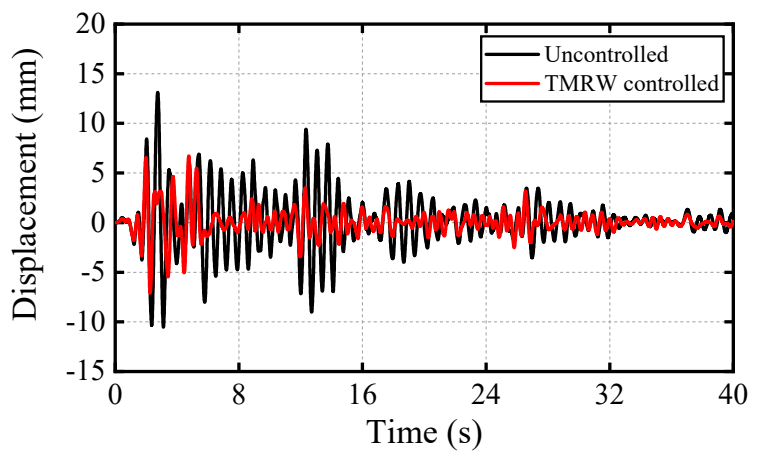

(a)

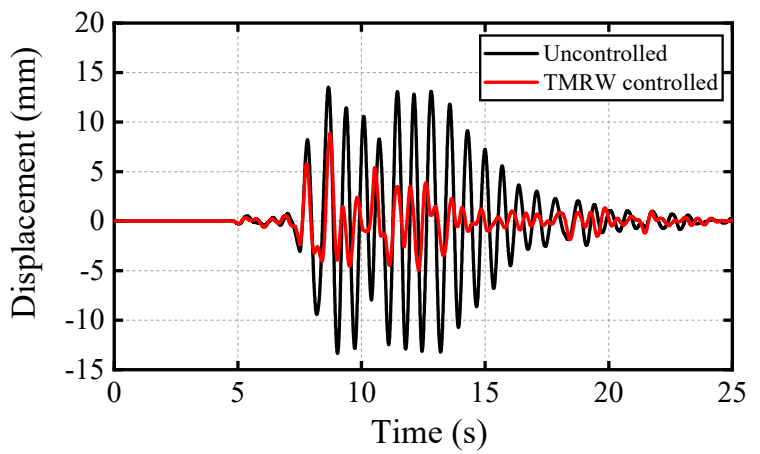

(b)

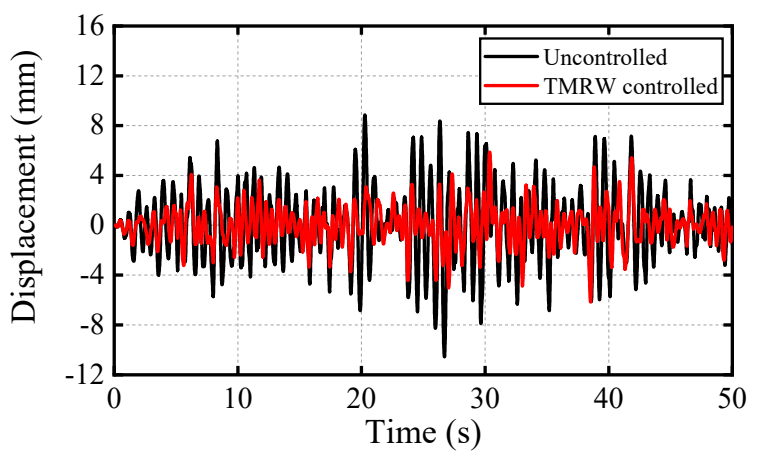

(c)

Figure 13. Comparison of displacement responses on the second floor: (a) El Centro earthquake excitation; (b) Kobe earthquake excitation; (c) Wenchuan earthquake excitation. 
Table 6. Control effectiveness of displacement responses on the second floor.

\begin{tabular}{ccccc}
\hline \multirow{2}{*}{ Excitation } & \multirow{2}{*}{ Value } & \multicolumn{2}{c}{ Displacement $(\mathbf{m m})$} & \multirow{2}{*}{$\boldsymbol{\eta}$} \\
\cline { 3 - 4 } & & Uncontrolled & TMRW & \\
\hline \multirow{2}{*}{ El Centro $(0.1 \mathrm{~g})$} & Peak & 13.120 & 7.101 & $45.9 \%$ \\
& RMS & 2.750 & 1.335 & $51.5 \%$ \\
\hline \multirow{2}{*}{ El Centro $(0.2 \mathrm{~g})$} & Peak & 25.158 & 14.050 & $44.2 \%$ \\
& RMS & 5.263 & 2.663 & $49.4 \%$ \\
\hline \multirow{2}{*}{ Kobe $(0.1 \mathrm{~g})$} & Peak & 13.518 & 8.865 & $34.4 \%$ \\
& RMS & 4.568 & 1.530 & $66.5 \%$ \\
\hline \multirow{2}{*}{ Kobe $(0.2 \mathrm{~g})$} & Peak & 29.593 & 17.949 & $39.3 \%$ \\
& RMS & 6.853 & 3.108 & $54.6 \%$ \\
\hline \multirow{2}{*}{ Wenchuan $(0.1 \mathrm{~g})$} & Peak & 10.553 & 6.157 & $41.7 \%$ \\
& RMS & 2.959 & 1.561 & $47.2 \%$ \\
\hline \multirow{2}{*}{ Wenchuan $(0.2 \mathrm{~g})$} & Peak & 19.692 & 12.276 & $37.7 \%$ \\
& RMS & 5.805 & 3.120 & $46.3 \%$ \\
\hline
\end{tabular}

\subsection{Acceleration Responses}

Figure 14 shows the control results when different earthquakes strike, and the acceleration responses on top of the host structure are compared. The results show that the TMRW control can also effectively improve the seismic performance by reducing earthquakeinduced acceleration, especially in the Kobe earthquake case. Under various excitation intensities, Table 7 compares the controlled and uncontrolled acceleration responses. As listed in Table 7, the reductions of the peak and the RMS acceleration responses are $44.4 \%$ and $53.7 \%$ under a low excitation intensity. As the intensity reaches $0.2 \mathrm{~g}$, the control effectiveness of the peak and the RMS acceleration responses is decreased by $23.6 \%$ and $16.5 \%$, respectively.

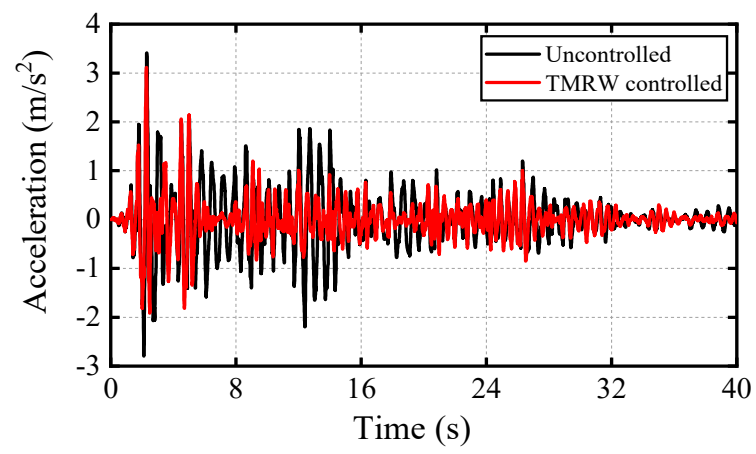

(a)

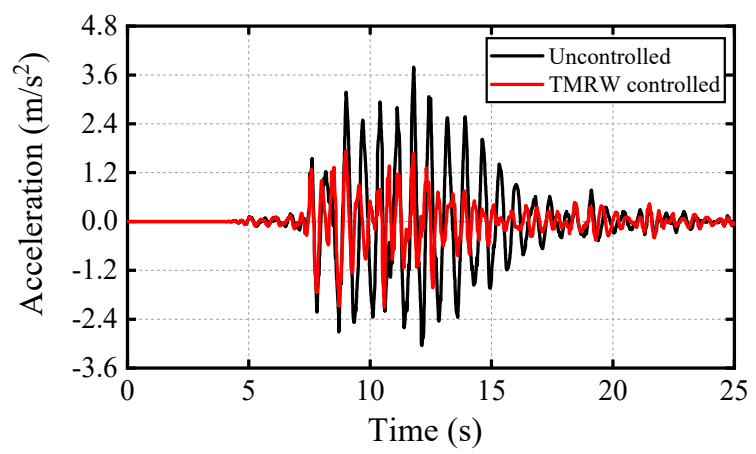

(b)

Figure 14. Cont. 


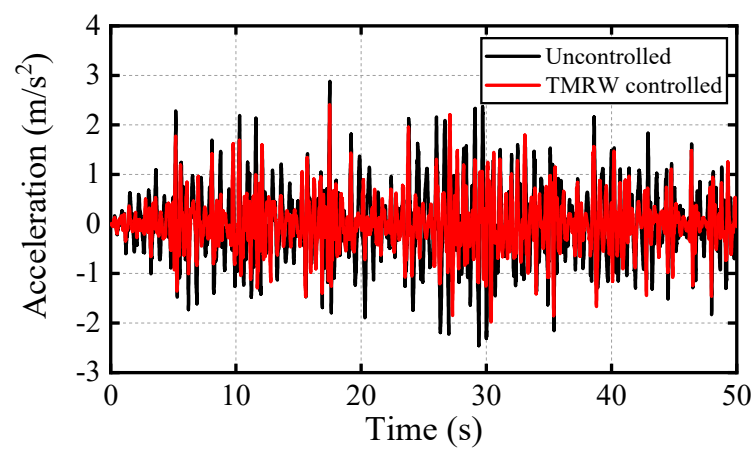

(c)

Figure 14. Comparison of acceleration responses on the top floor: (a) El Centro earthquake excitation; (b) Kobe earthquake excitation; (c) Wenchuan earthquake excitation.

Table 7. Control effectiveness of acceleration responses on the top floor.

\begin{tabular}{|c|c|c|c|c|}
\hline \multirow{2}{*}{ Excitation } & \multirow{2}{*}{ Value } & \multicolumn{2}{|c|}{ Acceleration $\left(\mathrm{m} / \mathrm{s}^{2}\right)$} & \multirow{2}{*}{$\eta$} \\
\hline & & Uncontrolled & TMRW & \\
\hline \multirow{2}{*}{ El Centro (0.1 g) } & Peak & 3.409 & 3.114 & $8.7 \%$ \\
\hline & RMS & 0.596 & 0.400 & $32.9 \%$ \\
\hline \multirow{2}{*}{ El Centro (0.2 g) } & Peak & 6.299 & 5.994 & $4.8 \%$ \\
\hline & RMS & 1.105 & 0.793 & $28.2 \%$ \\
\hline \multirow{2}{*}{ Kobe $(0.1 \mathrm{~g})$} & Peak & 3.791 & 2.107 & $44.4 \%$ \\
\hline & RMS & 0.918 & 0.425 & $53.7 \%$ \\
\hline \multirow{2}{*}{ Kobe $(0.2 \mathrm{~g})$} & Peak & 5.352 & 4.238 & $20.8 \%$ \\
\hline & RMS & 1.337 & 0.839 & $37.2 \%$ \\
\hline \multirow{2}{*}{ Wenchuan (0.1 g) } & Peak & 2.882 & 2.411 & $16.3 \%$ \\
\hline & RMS & 0.704 & 0.521 & $26.0 \%$ \\
\hline \multirow{2}{*}{ Wenchuan (0.2 g) } & Peak & 5.739 & 4.823 & $16.0 \%$ \\
\hline & RMS & 1.376 & 1.042 & $24.3 \%$ \\
\hline
\end{tabular}

\section{Conclusions}

Making use of the control principle of the traditional TMD, a new TMRW-controlled system is proposed and is believed to have a significantly improved ability on controlling the responses of host structures under earthquake excitations. Taking the six-story frame structure as an example, the dynamic time-history analysis is conducted to investigate the seismic performance of the TMRW-frame structure. The findings obtained from the theoretical analysis and numerical calculation show that:

- Considering the presence of the structural damping, the numerical parameter solution of the TMRW is different from the analytic parameter solution under harmonic excitation. Additionally, the optimal parameter values also differ based on whether the TMRW is designed for main mass excitation or base excitation.

- Using the dynamic amplification factor of the main mass, the analytical control result of the TMRW can be easily plotted. It is observed that TMRW- 1 and TMRW- 2 controls can both effectively reduce the steady-state amplitude of the main mass. For the TMRW-1 controlled system, the amplification factor at the tuning frequency is zero. On the other hand, the TMRW-2 controlled system can improve the deterioration of the TMRW performance caused by the change of the excitation frequency.

- By taking the six-story frame structure as the host structure, the uncontrolled and the TMRW-controlled cases were simulated and compared under different earthquake excitations. It can be seen that after adding the TMRW, the IDR values at each floor can be obviously reduced, especially the weak stories. Thus, the TMRW possesses the 
merit of controlling the deformation pattern of the frame structure. Note that due to the reduction of the connection stiffness, the compatible deformation capacity of the TMRW is not as good as the traditional rocking wall.

- While performing as a traditional TMD, the proposed TMRW can produce a good seismic performance in reducing earthquake-induced displacement and acceleration. It was found that TMRW control can achieve $45.9 \%$ and $66.5 \%$ reductions in the peak and RMS displacement, while the reductions of the peak and the RMS acceleration responses are $44.4 \%$ and $53.7 \%$. It was also observed that the control effectiveness of the TMRW tends to decrease when the intensity of the earthquake input increases.

- Theoretically, the TMRW system can reduce the seismic responses of frame structures. However, the applicability and the reliability of the proposed system should be verified through a series of tests before it can truly be used in some applications related to seismic engineering.

Author Contributions: Conceptualization, methodology, validation, investigation, A.W. and W.L.; software, A.W.; formal analysis, A.W. and W.L.; resources, A.W., W.L. and S.C.; data curation, A.W.; writing-original draft preparation, A.W. and W.L.; writing—review and editing, S.C. and A.Q.; visualization, W.L., S.C., A.Q. and Z.S.; supervision, A.Q. and Z.S. All authors have read and agreed to the published version of the manuscript.

Funding: This research was funded by the National Natural Science Foundation of China, grant number 51678158, 51578159, and 51878181 and the Natural Science Foundation of Fujian Province, China (No. 2018J01773, 2021J01602 and 2021J01602), the Science and Technology Major Project of the Science and Technology Department of Fujian Province (2019HZ07011).

Institutional Review Board Statement: Not applicable.

Informed Consent Statement: Not applicable.

Data Availability Statement: The data presented in this study are available on request from the corresponding author.

Conflicts of Interest: The authors declare that there is no conflict of interest regarding the publication of this paper.

\section{References}

1. Alavi, B.; Krawinkler, H. Strengthening of moment-resisting frame structures against near-fault ground motion effects. Earthq. Engng Struct. Dyn. 2004, 33, 707-722. [CrossRef]

2. Qu, Z; Ye, L. Seismic damage mechanism control of rocking wall-frame system. Earthq. Eng. Eng. Vib. 2011, 31, 40-50. (In Chinese)

3. Makris, N.; Aghagholizadeh, M. The dynamics of an elastic structure coupled with a rocking wall. Earthq. Engng Struct. Dyn. 2017, 46, 945-962. [CrossRef]

4. Grigorian, M.; Tavousi, S. Innovation in rocking wall-frame systems-theory and development. Int. J. Adv. Struct. Eng. 2017, 9, 205-217. [CrossRef]

5. Wang, S.; Wu, M. State-of-the-art and design methods on frame-rocking wall structures. Earthq. Eng. Eng. Dyn. 2020, 40, 154-163. (In Chinese)

6. Masrom, M.A.; Hamid, N.H.A. Review on the rocking wall systems as a self-centering mechanism and its interaction with floor diaphragm in precast concrete structures. Lat. Am. J. Solids Struct. 2020, 17, e291. [CrossRef]

7. Qu, Z.; Wada, A.; Ye, L. Seismic retrofit of frame structures using rocking wall system. J. Build. Struct. 2011, 32, 11-19. (In Chinese)

8. Qu, Z.; Wada, A.; Motoyui, S.; Sakata, H.; Kishiki, S. Pin-supported walls for enhancing the seismic performance of building structures. Earthq. Engng Struct. Dyn. 2012, 41, 2075-2091. [CrossRef]

9. Feng, Y.; Wu, J.; Meng, S.; Wang, Q.; Fu, K. Aseismic performance analysis of rocking wall frame structures with bucklingrestrained braces in base. Vib. Shock 2016, 35, 35-40. (In Chinese)

10. Guo, G.; Qin, L.; Yang, D.; Liu, Y. Dimensional response analysis of rocking wall-frame building structures with control devices subjected to near-fault pulse-like ground motions. Eng. Struct. 2020, 220, 110842. [CrossRef]

11. Aghagholizadeh, M.; Makris, N. Response analysis of yielding structures coupled to rocking walls with supplemental damping. Earthq. Engng Struct. Dyn. 2021, 50, 2672-2689. [CrossRef]

12. Xiang, P.; Nishitani, A. Structural vibration control with the implementation of a pendulum-type nontraditional tuned mass damper system. J. Vib. Control 2017, 23, 3128-3146. [CrossRef]

13. Di Egidio, A.; Pagliaro, S.; Fabrizio, C.; de Leo, A.M. Seismic performance of frame structures coupled with an external rocking wall. Eng. Struct. 2020, 224, 111207. [CrossRef] 
14. Wang, A.; Chen, S.; Lin, W.; Qi, A. Seismic performance analysis of tuned mass rocking wall (TMRW)-frame building structures. Buildings 2021, 11, 293. [CrossRef]

15. Randall, S.E.; Halsted, D.M.; Taylor, D.L. Optimum vibration absorbers for linear damped systems. J. Mech. Design 1981, 103, 908-913. [CrossRef]

16. $\mathrm{Wu}, \mathrm{K} . ;$ Ren, C.; Chen, Y. Vibration control of time-varying delay under complex excitation. Micromachines 2021, 12, 1081. [CrossRef]

17. Wu, K.; Ren, C.; Chen, Y. Time-delay vibration reduction control of a 3-DOF vehicle model with vehicle seat. Micromachines 2021, 11, 9426. [CrossRef]

18. Pian, C.; Liu, Z.; Tao, Y.; Lu, G. Revised plasticity damaged constitutive model of reinforced concrete equivalent material and its application in seismic analysis. Build. Struct. 2015, 45, 19-24. (In Chinese) 